\title{
Triatoma sordida: indicadores de adaptación y transmisión de Trypanosoma cruzi en intradomicilio del Chaco Paraguayo
}

Zunilda Sánchez ${ }^{\mathrm{I}}$ Graciela Russomando ${ }^{\mathrm{I}}$, Lilian Chena ${ }^{\mathrm{I}}$, Eva NaraI, Edgar CardozoI Berta ParedesII Elizabeth Ferreira'

I Departamento de Biología Molecular y Biotecnología, Instituto de Investigación en Ciencias de la Salud, Universidad Nacional de Asunción. Paraguay

II Laboratorio de Entomología, SENEPA, Ministerio de Salud Pública y Bienestar Social. Paraguay

Cómo referenciar este artículo/ How to reference this article:
Sánchez Z, Russomando G, Chena L, Nara E, Cardozo E, Paredes B et al. Triatoma sordida indicadores de adaptación y transmisión de Trypanosoma cruzi en intradomicilio del Chaco Paraguayo. Mem. Inst. Investig. Cienc. Salud. 2016;14(3): 96-101

\section{R E S U M E N}

El gran Chaco es una eco-región que incluye Argentina, Bolivia y Paraguay; donde la trasmisión vectorial de la enfermedad de Chagas por Triatoma infestans (vector principal), constituye hasta la fecha un problema de salud pública. El Chaco paraguayo ocupa el $25 \%$ de esta región, caracterizada por una baja densidad poblacional y localidades dispersas. El objetivo de este estudio fue determinar el rol potencial de la especie Triatoma sórdida (vector secundario) en el ciclo doméstico de transmisión de Trypanosoma cruzi. Se aplicaron técnicas moleculares asociadas a indicadores entomológicos y epidemiológicosa436 ejemplares de $T$. sordida capturados en 147 viviendas del Chaco Paraguayo. Se detectó infestación y colonización en el intradomicilio y peridomicilio por $T$. sordida en $12(8.2 \%)$ y $79(53.7 \%)$ viviendas de las 147 evaluadas, respectivamente. Al menos un ejemplar infectado con $T$. cruzi fue detectado por PCR en las 12 viviendas con colonización intradomiciliar y en dos de ellas por caracterización molecular se detectó en ninfas el genotipo TC2. Adultos y ninfas en el peridomicilio de 4 viviendas dieron positivo para el genotipo TC1. Se estima un elevado riesgo de transmisión de $T$. cruzi intradomiciliar del $87 \%$.Estos resultados evidencian capacidad adaptativa de esta especie en el domicilio, y un incremento de su potencial vectorial para transmitir la enfermedad de Chagas en el Chaco Paraguayo.

Palabras claves: $T$. cruzi, genotipos, T.sordida, infestación, colonización

\section{Triatoma sordida: indicators of adaptive capacity and Trypanosoma cruzi intradomicile transmission in the Paraguayan Chaco}

\section{A B S T R A C T}

The Gran Chaco is an eco-region that includes Argentina, Bolivia and Paraguay; where the vectorial transmission of Chagas disease by Triatoma infestans (main vector) is a public health problem up to date. The Paraguayan Chaco occupies $25 \%$ of this region, characterized by low population density and dispersed locations. The aim of this study was to determine the potential role of the specie Triatoma sordida (secondary vector) in the domestic cycle of transmission of Trypanosoma cruzi. Molecular techniques associated with entomological and epidemiological indicators were applied in 436 specimens of $T$. sordida captured in 147 dwellings of the Paraguayan Chaco. Infestation rate and colonization by $T$. Sordida was detected in the intradomicile and peridomiciliary in $12(8.2 \%)$ and $79(53.7 \%)$ of the 147 dwellings, respectively. In 12 houses were colonization was observed, at least one specimen was PCR-T. cruzi positive, and in two of them genotype TC2 of $T$. cruzi were Fecha de recepción: septiembre 2016. Fecha de aceptación: noviembre 2016

Autores correspondiente: Zunilda Sanchez y Graciela Russomando. Departamento de Biología Molecular y Biotecnología, IICS, UNA

E-mail: zunysanchez@hotmail.com grusso@rieder.net.py 
detected innymphs by molecular characterization. Adults and nymphs in the peridomiciliary of 4 houses were positive for genotype TC1.A high risk of indoor transmission of $T$. cruzi is estimated in $87 \%$. These results demonstrate adaptive capacity of this specie in the intradomicile, and increased vector potential to transmit Chagas disease in the Paraguayan Chaco.

Keywords: $T$. cruzi, genotypes, $T$. sordida, infestation, colonization.

\section{INTRODUCCIÓN}

En la enfermedad de Chagas el principal vector transmisor del Trypanosoma cruzi (agente causal) en la Región del Cono Sur de América Latina, es el Triatoma infestans. Esta vía de transmisión ha disminuido notablemente en la última década, gracias a las decisiones políticas y técnicas de los países que con actividades sostenidas de control vectorial han logrado el corte de la transmisión intradomiciliar de $T$. cruzi por esta especie(1-3).

En la actualidad existe un riesgo permanente de re-infestación de las viviendas desde focos residuales de $T$. infestans como también el riesgo de la invasión de viviendas por especies secundarias si no se llevan a cabo acciones de vigilancia entomológica sostenidas en el tiempo y espacio $(4,5)$. Los patrones ecológicos de estos vectores se han modificado por el efecto de la deforestación de bosques tropicales $(6,7)$.

Muchas de las especies nativas adquieren importancia epidemiológica debido a la capacidad de intercambio entre hábitats selváticos y domésticos, así como por su potencialidad para reemplazar el nicho ecológico de triatominos estrictamente domiciliarios, luego de la disminución de estas especies por la acciones de control y vigilancia vectorial(8). Por esta razón es importante considerar la presencia de especies nativas de focos selváticos en proceso de colonización de las viviendas humanas y que son clasificados como vectores potenciales para la transmisión de la enfermedad, tales como las especies: Triatoma sordida, Triatoma guasayana, Pastrongilus megistus y otros $(9,10)$.

T.sordida está asociado como fuente de re-infestación de viviendas tratadas con insecticidas (11). Se ha descrito que en la región del Chaco paraguayo, tanto el control vectorial como la vigilancia entomológica se ve afectado por el aislamiento de las viviendas y problemas de acceso que unidos a las costumbres culturales de los habitantes (tribus indígenas), hace que aún persistan viviendas infestadas, a pesar de los esfuerzos realizados por el servicio nacional de control vectorial ${ }^{\mathbf{1 0}}$. El Programa Nacional de Chagas realiza actividades de vigilancia entomológica en áreas endémicas, en el Chaco. En un reporte del año 2013 se indica que fueron evaluadas entomológicamente 1.840 viviendas y rociadas 1.100 viviendas, capturando 663 ejemplares de $T$. sórdida y colonización intradomiciliar del $T$. sordida en las viviendas (12).Se realizó este estudio con el fin de obtener indicadores que permitan inferir sobre el potencial de $T$. sórdida como vector en la transmisión de la enfermedad de Chagas en esta región del país.

\section{MATERIALES Y MÉTODOS}

Área de estudio y población: Se analizaron 436ejemplares de $T$. sordida capturados entre los años 2010-2013 en 147 viviendas de 40localidades dispersas en los tres departamentos de la Región Occidental o Chaco. En Alto Paraguay los ejemplares fueron capturados en 64 viviendas ubicadas en 9 localidades dispersas en 2 distritos; mientras que en Boquerón y Pte. Hayes, los ejemplares fueron capturados en 51 y 32 viviendas, ubicadas en 18 y 15 localidades de 3 y 4 distritos, respectivamente. Datos epidemiológicos como sitio de captura y estado evolutivo de los triatominos fueron registrados en cada vivienda.

Los ejemplares de $T$. sordida fueron previamente clasificados taxonómicamente según Lent y Wygodzinsky (13) por especie y estado evolutivo, en el Departamento de Entomología del SENEPA, y fueron remitidos al Dpto. de Biología Molecular y Biotecnología del IICS donde se conservaron a $-20^{\circ} \mathrm{C}$ hasta su procesamiento. Cabe resaltar que no se han detectado triatominos de la especie $T$. infestans y $T$. guasayana en las localidades donde fueron capturados los ejemplares de $T$. sordida durante el periodo del presente estudio.

El peridomicilio de las viviendas del Chaco Paraguayo se caracteriza por no contar con una delimitación entre el área silvestre y las viviendas. Esto se observa mayormente en las poblaciones indígenas, mientras que en las viviendas de menonitas y paraguayos criollos la 
acumulación de leña y gallineros es lo más resaltante. Animales domésticos, principalmente perros se observa en la mayoría de las viviendas.

Disección de triatominos: Se realizó la disección de los insectos para realizar la extracción de ADN de cada ejemplar, cada uno de los 436 ejemplares disectados fue colocado en tubos y se resuspendieron en buffer de lisis compuesto por solución Tris pH 7,4, EDTA, $\mathrm{NaCl}$ y SDS.

Extracción de ADN: Se realizó la incubación de cada tubo con $5 \mu$ lde proteinasa K (20 $\mu \mathrm{g} / \mathrm{mL}$ ) a $60^{\circ} \mathrm{C}$ por 1 hora. La enzima fue inactivada por calentamiento a $95^{\circ} \mathrm{C}$ por 10 minutos. El ADN fue purificado por el método de extracción: fenol-cloroformo descrito por Sambrook et al. (14)y precipitación con etanol, previa adición de $20 \mu \mathrm{g}$ de glucógeno y acetato de sodio $3 \mathrm{M}$, pH 5,4 en un $10 \%$ del volumen recuperado. El sedimento de ADN se disolvió en $100 \mu \mathrm{L}$ de agua destilada estéril.

Infección natural con T.cruzi y caracterización molecular:

La identificación especie específica de $T$. cruzi fue por el método PCR empleando como blanco las secuencias repetitivas de ADN nuclear (microsatélites) de T.cruzi, utilizando los cebadores TCZ1 y TCZ2 descrito por Moser et al.(15).

La identificación de genotipos de T.cruzi: se realizó por medio de la amplificación del gen constitutivo de la región del mini-exón (16).

Los productos amplificados fueron analizados en geles de agarosa al $2 \%$, teñidos con bromuro de etidio y visualizados bajo un transiluminador UV (16).

\section{RESULTADOS}

Se recibieron en el laboratorio un total de 436 ejemplares de $T$. sordida, colectados de 147 viviendas del Chaco en el periodo 2010-2013. La captura de ejemplares en cada vivienda es una actividad realizada dentro de la vigilancia entomológica, en localidades previamente fumigadas por la presencia de $T$. infestans. No se han registrado otras especies en intradomicilio o peridomicilio de las viviendas incluidas en este estudio.

En relación al lugar de captura y estadio, se observó que $12(8.2 \%)$ y $79(53.7 \%)$ de las 147 viviendas evaluadas estaban infestadas con ninfas en el domicilio y peridomicilio, respectivamente (tabla 1). En el intradomicilio de las 23 viviendas se capturaron 69 ejemplares de los cuales $33(47.8 \%)$ estaban infectados con T. cruzi (tabla 2 ).

Tabla 1. Distribución de las 147 viviendas infestadas con $T$. sordida según el sitio de captura, colonización y ejemplares infectados con $T$. cruzi.

\begin{tabular}{|c|c|c|c|c|}
\hline \multirow[b]{2}{*}{$\begin{array}{l}\text { Estadío de } \\
\text { ejemplares } \\
\text { capturados }\end{array}$} & \multicolumn{4}{|c|}{$\mathrm{N}^{\circ}$ de viviendas con $T$. sordida } \\
\hline & $\begin{array}{l}\text { INTRADOMICILIO } \\
\text { Total infestadas }\end{array}$ & $\begin{array}{l}\text { Viviendas con } \\
\text { ejemplares } \\
\text { infectados con } T \text {. } \\
\text { cruzi }(* *)\end{array}$ & $\begin{array}{l}\text { PERIDOMICILIO } \\
\text { Total infestadas }\end{array}$ & $\begin{array}{l}\text { Viviendas con } \\
\text { ejemplares } \\
\text { infectados con } \\
\text { T. cruzi }(* *) \\
\end{array}$ \\
\hline Ninfas $(*)$ & $12(8.2 \%)$ & $12(100 \%)$ & $79(53.7 \%)$ & $30(38 \%)$ \\
\hline $\begin{array}{l}\text { Solo ejemplares } \\
\text { adultos }\end{array}$ & $11(7.5 \%)$ & $8(72.7 \%)$ & $45(30.6 \%)$ & $20(44.4 \%)$ \\
\hline Total & $23(15.7 \%)$ & $20(87 \%)$ & $124(84.4 \%)$ & $50(40.3 \%)$ \\
\hline
\end{tabular}

* La presencia de ninfas en el domicilio de las viviendas es un indicador de colonización, se han detectado ejemplares adultos en las viviendas colonizadas.**Viviendas donde se ha detectado al menos un ejemplar infectado con T. cruzi 
Tabla 2. Distribución de 436 ejemplares de $T$. sordida según estado evolutivo, lugar de captura e infección con $T$. cruzi.

\begin{tabular}{lllll}
\hline \multirow{2}{*}{ ESTADO EVOLUTIVo } & \multicolumn{4}{c}{$\mathbf{N}^{\circ}$ de ejemplares de T. sordida } \\
\cline { 2 - 5 } & INTRADOMICILIO & $\begin{array}{l}\text { Infección } \\
\text { con } \boldsymbol{T} \text {. cruzi }\end{array}$ & PERIDOMICILIO & $\begin{array}{l}\text { Infección con } \\
\text { T. cruzi }\end{array}$ \\
\hline Ninfas & 37 & $21(56.8 \%)$ & 170 & $37(21.8 \%)$ \\
Adultos & 32 & $12(37.5 \%)$ & 197 & $22(11.2 \%)$ \\
Total & $\mathbf{6 9}$ & $\mathbf{3 3}(\mathbf{4 7 . 8 \% )}$ & $\mathbf{3 6 7}$ & $\mathbf{5 9 ( 1 6 . 1 \% )}$ \\
\hline
\end{tabular}

Un total de 92 (21\%) ejemplares de los 436 capturados dieron positivo por PCR para $T$. cruzi. En 6 ejemplares se pudo determinar el genotipo TC1 o TC2 por amplificación del miniexon, adultos y ninfas capturados en peridomicilio con el genotipo TC1 (selvático), y ninfas capturadas en intradomicilio con el genotipo TC2 (domiciliar).

En la figura 1 se puede observar los productos de amplificación de 300 pb y 350 pb del gen mini- exón, para la determinación de los genotipos de $T$. cruzi.

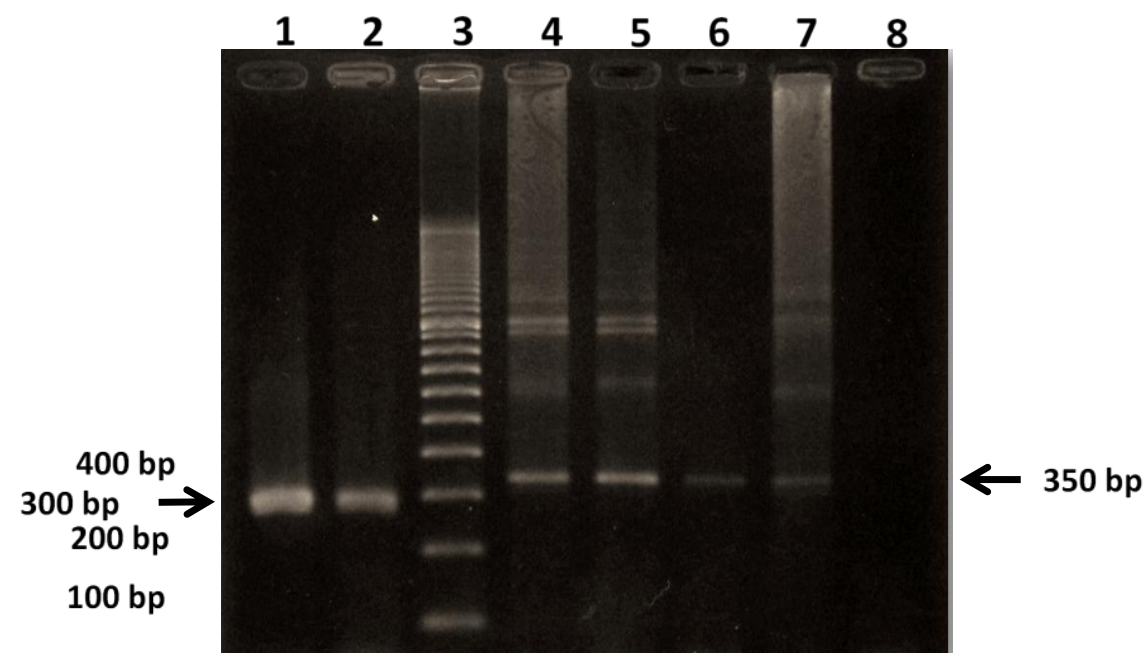

Figura 1. Amplificación de ADN del gen mini-exón para determinación de linajes de T. cruzi. Carril 1: producto de amplificación de control positivo de TC2; cepa de referencia $\mathrm{MNcl}_{1}\left({ }^{7}\right)$ de $300 \mathrm{pb}$. Carril 2: producto de $300 \mathrm{pb}$ correspondiente a una muestra de $T$. sordida (TC2). Carril 3: Marcador de peso molecular (100 pb).Carril 4: producto amplificado de control positivo de TC1; cepa de referencia $\mathrm{X}_{10} \mathrm{Cl}_{2}\left({ }^{7}\right)$ de $350 \mathrm{bp}$. Carriles 5, 6, 7: productos de $350 \mathrm{pb}$ (TC1) correspondientes a tres muestras de $T$. sordida. Carril 8: Control negativo de reacción de PCR (H2O).

\section{DISCUSIÓN}

En el presente trabajo se describe uno de los mayores índices de infestación intradomiciliar por T. Sórdida (15.7\%), en donde el $87 \%$ de las viviendas infestadas presentaban al menos un ejemplar infectado con $T$. cruzi. Otros autores han descrito infestación intradomiciliar de $T$. sordida en áreas previamente ocupadas por $T$. infestans, pero con un índice de infestación e infección natural inferior (17-19) al observado en este trabajo.

La preferencia de $T$. sordida en el peridomicilio sigue siendo mayor con respecto al domicilio, teniendo en cuenta que de las 147 viviendas infestadas 124 (84.4\%) presentaban como sitio de captura el peridomicilio. Sin embargo, se evidencia un alto riesgo de transmisión vectorial intradomiciliar por $T$. sordida, si consideramos que en las $12(100 \%)$ viviendas colonizadas de las 23 viviendas totales infestadas en el intradomiciliose detectó al menos un ejemplar infectado naturalmente con $T$. cruzi. 
Se observa un elevado índice de infección natural que supera a lo publicado hasta la fecha, mayor en los triatominos capturados en el intradomicilio que en los encontrados en el peridomicilio, con índices del 47.8\% (33 infectados de 69 capturados y $16.1 \%$ (59 infectados de 367 capturados), respectivamente. En otros países de la región, como en Bolivia donde $T$. sordida es la segunda especie considerada de importancia epidemiológica, un estudio realizado en el Dpto. de Santa Cruz (corresponde a la eco-región del Chaco), han reportado la presencia de $T$. cruzi en un $16,2 \%$ de los ejemplares de $T$. sordida del intradomicilio (20).

Triatoma sordida representa un problema epidemiológico en numerosos países del Cono Sur debido a su amplia valencia ecológica, que se manifiesta en su hallazgo en biotopos silvestres, peridomésticos, así como dentro de la vivienda (21).En Argentina, existen publicaciones que indican desde el $2 \%$ hasta el $12 \%$ de infección natural en ejemplares de T. sórdida capturados en el peridomicilio $(22,23)$.

La densidad de ejemplares de $T$. sordida en el peridomicilio es mayor que en el domicilio, 367 triatominos en 80 viviendas y 69 triatominos en 67 viviendas, respectivamente; lo que evidencia una adaptación aún fuerte de $T$. sórdida al peridomicilio.

Concluimos que en la Región del Chaco Paraguayo existe un alto riesgo de transmisión vectorial intradomiciliar de $T$. cruzi por $T$. sordida si tenemos en cuenta el número de ejemplares de $T$. sordida capturados en el intradomicilio (colonización), la elevada infección natural y la detección del genotipodoméstico TC2 en ejemplares de $T$ sordida en dos viviendas. Los resultados obtenidos en este estudio permiten inferir que existe un alto riesgo de transmisión vectorial de la enfermedad de Chagas por $T$. sordida. Se evidencia una fuerte invasión de esta especie en el domicilio de viviendas del Chaco Paraguayo, un vector nativo y con adaptación demostrada al peridomicilio. No existían hasta la fecha indicadores fuertes de adaptación al intradomicilio, por lo que el presente trabajo adquiere relevancia para las acciones de control vectorial y vigilancia epidemiológica en la Región del Gran Chaco.

\section{REFERENCIAS BIBLIOGRAFÍA}

1. Schmunis GA, Dias JCP. Health care reform, decentralization, prevention and control of vector-borne diseases. Cad SaúdePública.2000; 16:117-23.

2. Dias JCP, Silveira AC, Schofield CJ. The impact of Chagas disease control in Latin America: areview. Mem Inst Oswaldo Cruz. 2002; 97:603-12.

3. Silveira, AC; Rojas de Arias A; Segura E; Guillén G; Russomando G; Schenone $\mathrm{H}$; Pinto Dias JC; Valdes Padilla J; Lorca M; Salvatella R. El control de la Enfermedad de Chagas en los países del Cono Sur de América. Historia de una Iniciativa Internacional. 1991/2001. OPAS, Universidade Federal do Triângulo Mineiro, Uberaba; 2002. p. 316pp.

4. Noireau F. Gutierrez $T$, Flores R. Brenier F, Bosseno MF, WisniveskyColli C. Ecogenetics of $T$. sordida and $T$. guayasana (Hemiptera: Reduviidae) in the Bolivian Chaco. Mem Inst Oswaldo Cruz. 1999; 94(4): 451-57.

5. OPS Organización Panamericana de la Salud. Taller del Cono Sur enfermedad de Chagas. Conceptualización de la vigilancia epidemiológica. Bs. As. Argentina. 2003.

6. Walsh J, Molineux D, Birley $M$. Deforestación: Effectson vector-borne disease. Parasitology 1993; 106 (suppl.1): 55-75.

7. Zingales $B$, Souto $R$, Mangia R, Lisboa C, Campbell D, Coura J, Jansen A, Fernández O. Molecular epidemiology of Americam Trypanosomiasis in Brasil based on dimorphism of rRNA and mini-exón gene sequence. Int.J. Parasitol 1998; 28: 105-12.

8. Noireau $F$, Flores $R$, Gutierrez $T$, Abad-Franch $F$, Flores $E$, Vargas $F$. Natural ecotopes of Triatoma infestans dark morph and other sylvatic triatomines in the Bolivian Chaco. Trans R Soc Trop Med Hyg 2000; 94: 23-7.

9. Lent $H$, Wygodzinsky $P$. Revision of Triatominae (Hemiptera: Reduviidae), and the other significanse as vectors of Chagas disease. Bull Am Mus Nat Hist 1979; 163: 123-27.

10. González-Britez N, Vega C, Rolón M, Rojas de Arias A. Triatomines and other arthopods in bird nests in native and Mennonite communities of the Paraguayan Chaco. Abstracts of 
Sanchez et al. Triatoma sordida: indicadores de adaptación y transmisión de Trypanosoma cruzi en intradomicilio $\mathrm{XV}{ }^{\mathrm{TH}}$ Internacional Congress for Tropical Medicine and Malaria, Cartagena-Colombia 2000; (2): 89.

11. Diotaiuti L, Paula OR, Falcão PL, Dias JCP. Avaliação do programade controle vectorial dado ença de Chagas emb v Minas Gerais, Brasil, com referencia especial ao Triatoma sordida. Bol Oficina Sanit Panam.1995;118(3):211-9.

12. Programas del SENEPA. Programa Nacional de Control de la Enfermedad de Chagas. Situación epidemiológica actual, a la semana 18, año 2013. Disponible en: http://programassenepa.blogspot.co $\mathrm{m} / \mathrm{p} /$ chagas.html.

13. Lent $H$, Wygodzinsky P. Revision of the Triatominae (Hemiptera: Reduviidae), and their significance as vectors of Chagas disease. Bull Am Mus Nat Hist. 1979; (163): 125-520.

14. Sambrook J, Fritsch E and Maniatis T. Molecular Cloning. A Laboratory Manual.Cold Spring Harbor Laboratory Press. New York E.U.A 1994.

15. Moser DR, Kirchhoff LV, Donelson JE. Detection of Trypanosoma cruzi by DNA amplification using the polymerase chain reaction. J Clin Microbiol. 1989; (7): 1477-82.

16. Brisse S, Verhoef J, Tibayrenc M. Characterisation of large and small subunit rRNAand mini-exón genes further supports the distinction of six Trypanosoma cruzi lineages. Int. J Parasitol. 2000; (31): 1218-26.

17. Forattini OP, Barata JMS, Santos JLF, Silvera AC. Hábitos alimentares: infeccao natural e distribuicao de triatomíneos domiciliados naregiao central do Brasil. Rev. Saúde Públ. 1982; 16, 171-204.

18. Noireau F, Breniere F, Ordoñez J, Cardozo L,Morochi W, Gutierrez T, Bosseno MF, García S, Vargas F, Yaksic N, Dujardin JP, Peredo C, Wisnivesky-Colli C. Lowprobability of transmission of Trypanosoma cruzi to humans by domiciliary Triatoma sordida in Bolivia. Trans. R. Soc. Trop. Med. Hyg. 1997; 91, 653-6.

19. Macchiaverna NP, Gaspe MS, Enriquez GF, Tomassone L, Gurtler R E, Cardinal MV. Trypanosoma cruzi infection in Triatoma sordida before and after community-wide residual insecticide spraying in the Argentinean Chaco. Acta Tropica. 2015; 143, 97-102.

20. Breniere SF, Morochi W, Bosseno MF, Ordoñez J, Gutierrez T, Vargas F, Noireau F. Trypanosoma with domestic Triatoma sordida in Bolivia. ActaTropica 71.1998; 269-83.

21. World Health Organization. Control of Chagas Disease. Second report of the WHO Expert Committee. WHO Tech Rep Ser 2002; 905: 1-109.

22. Oscherov EB, Bar ME, Damborsky MP, Milano A, Avalos G, Borda M. Epidemiología de la enfermedad de Chagas, Departamento General Paz, Argentina. RevSaúdePública. 2003; 37(1):59-64.

23. Bar ME, Wisnivesky-Colli C. Triatoma sordid Stal 1859 (Hemiptera, Reduviidae: Triatominae) in palms of northeastern Argentina. Mem Inst Oswaldo Cruz. 2001;(96): 895-9. 